\title{
Hearing Indigenous Voices in Mainstream Social Work
}

\author{
Mel Gray, John Coates, \& Tiani Hetherington
}

\begin{abstract}
In this paper we attempt to counter misconceptions about the silencing of Indigenous voices in mainstream social work. We contend that Indigenous voices are present in several emerging bodies of mainstream social work literature, such as the literature on spirituality and ecosocial work, but most social workers do not hear them because they are more inclined to turn to the crosscultural or anti-oppressive practice literature, predominantly in the United States and United Kingdom, respectively, when seeking answers for issues relating to diversity in social work. Few look to the Indigenous social work literature. Thus the central question this article addresses is 'what might we learn about diversity and culture from the Indigenous social work literature that might inform mainstream culturally relevant social work practice?'
\end{abstract}

Social work, like "sailing, gardening, politics and poetry, law and ethnography are crafts of place: They work by the light of local knowledge." (Geertz, 1983, p. 67)

$\mathbf{W}$ ithin the mainstream social work literature notions of difference or diversity have been dealt with in a variety of ways. This has spawned several bodies of knowledge relating to, inter alia, cross-cultural and anti-oppressive social work practice. Culturally and racially sensitive practice models, then, form part of Western social work's attempt to deal with difference. Critical theorists have been quick to point out the way in which minority and Indigenous voices have been silenced within this dominant social work discourse.

We contend that globalizing and universalizing forces continue the profession's colonizing tradition by which Western social work models have supplanted local,
Indigenous approaches and practices. We argue that these trends are reigniting Indigenous resistance. At the same time, in those contexts where social workers and Indigenous communities have been interacting and working in close proximity with one another, Indigenous voices are finding some expression in the mainstream literature, notably in the areas of spirituality and environmental social work. In these contexts, this discourse has progressed beyond multiculturalism, cultural sensitivity, and antioppressive practice to embrace Indigenous thinking and practices. Examples are provided from Australia, Canada, New Zealand (Tonga), China, Malaysia, and India. They highlight the importance of culture and local knowledge in the development of genuine and authentic social work practice in these contexts.

We want to promote the fact that Western social workers have as much to learn from Indigenous social workers as Indigenous social workers have to learn from Western 
social workers. Thus the lessons learned in Indigenous contexts have application in Western contexts, especially in situations where social workers are dealing with diversity. Therefore, we want to address the imbalance in the literature on cross-culturalism that is largely directed toward Western social workers practicing within culturally diverse client communities in Western contexts, where it embraces many of the ideas of antiracist and anti-oppressive practice. In fact, this literature conflates discussions of race, culture, and all forms of discrimination and subsumes it under critically constructed anti-oppressive practice theory (which remains a theory in search of a practice-for these ideas are still highly interpretive and beyond the reach of empirical validation). This is not surprising given that most Indigenous groups are minority populations of color (with few exceptions, for example, black majority South Africans under apartheid) who have historically experienced oppression from colonizing nations that have undermined their efforts at self-government and, therefore, self-determination.

While there is much of value in the cross-cultural literature, there is also much to be gained from the Indigenous social work literature. (iray and Allegritti $(2002,2003) \mathrm{con}^{-}$ tended that culture was central to the indigenization debate in social work. If there were to be a single perspective emanating from this article, it would be an appeal to internationalizing social work, by which we mean, impressing on social workers across the world, whether in Western or Indigenous contexts, to be aware $o$, and pay attention to one another's work for each has implications for the other (Gray \& Fook, 2004; Gray, 2005). In this vein, the central question of this article is, what might we learn about culture from the Indigenous social work literature that might inform mainstream culturally relevant social work practice? Being mindful of our mainly North American audience in this instance, we nevertheless believe that the issues raised herein should be of concern to all social workers everywhere,-practitioners, researchers and educators alike.

\section{Lessons From the Indigenous Social Work Literature}

A review of the literature on Indigenous social work reveals a great deal of negativity around the world on social work's track record in working across cultures and with Indigenous people (Ling, 2003; Nagpaul, 1993; Nimmagadda \& Cowger, 1999; Tsang \& Yan, 2001; 'Tsang, Yan, \& Shera, 2000; Yip 2004). This is not surprising given that social work is essentially a modernist Western invention that has a history of silencing Indigenous voices and importing, into diverse cultural contexts across the world, Western thinking from Britain and the United States. Indigenous social work can be seen as a movement within social work to counter these colonializing. Westernizing, globalizing, Americanizing forces.
For Indigenous people, all these 'izings' mean the same thing - the rising of Western models and the sinking of local Indigenous wisdoms, knowledges, and moralities. Indigenization is a movement proclaiming, "we want to dance to the beat of our own drums," and it is one with which current universalizing trends within social work are totally out of step. We refer here to trends to find a universal definition of, and global qualifying education standards for, social work. While not eschewing the value of a common discourse on and understanding about social work, we need to be mindful that there is another 'izing' as Western values are being imposed from the top down. "The globalization of knowledge and Western culture constantly reaffirms the West's view of itself as the center of legitimate knowledge, the arbiter of what counts as knowledge and the source of "civilized' knowledge" (Smith, quoted in Hart, 2002, p. 29). These professionalizing trends define boundaries and keep out those who do not conform. They are guided more by social work's professional interests-to give social workers and social work education programs status in society-than by the interests and needs of local communities to whom we are, in theory any way, meant to be responsive and accountable. Indigenous movements usually involve people collectively asserting their rights for self-determination since Indigenous people recognize that political, economic, educational, and health benefits and privileges cannot occur as long as the entire population is disenfranchised. Self-determination for Indigenous people has greater meaning in the sense that it concerns the empowerment of entire populations. The self-directing potential of individuals cannot be increased without considering historical, social, cultural, economic, and political realities.

Against this broader political reality, the literature on spirituality and environmental social work (aka green or ecosocial work) articulates and privileges local Indigenous cultures, to use anti-oppressive terminology, but more important, it is a countermovement to the universalizing movement in social work and beyond through globalization. Spirituality, a path that seeks greater connection to larger purposes and meaning, celebrates diversity and promotes inclusion. Ecosocial work draws on a deep cological awareness of our relationship with nature and the importance of protecting and sustaining the natural environment in everyone's interests. It needs to be distinguished from ecological social work, which tends to take an anthropocentric stance focusing on the social environment from the point of view of human or individual interests (Besthorn, 1997; Coates, 2003).

The growing acceptance and recognition of spirituality and ecology with their emphasis on alternative worldviews have brought forth a welcoming and inclusive context enabling the celebration of diversity and the sharing of knowledge. The expanded understanding of person-inenvironment to assume an interdependence and relatedness 
to the Earth, the importance of place, and the openness to more traditional Indigenous forms of healing and helping are a refreshing "welcome mat" as they start from a set of values and beliefs that are central to Indigenous helping approaches. It creates opportunities for social work to make culture an implicit part of professional education and practice. We end up with multiple forms of interventions rather than a simpler, modern, and universal technology. In this article, we provide evidence of this drawing from examples of interactions between mainstream and Indigenous social workers in India, Malaysia, China, Canada, New Zealand (Tonga), and Australia. To Indigenous people, globalization is just a new form of colonialism.

\section{How Indigenization Fits With Cultural Competence}

Generally the literature on cross-cultural practice in social work flows from the idea that there is a particular body of cultural knowledge, values, and skills, and "layers of understanding" (Devore \& Schlesinger, 1995, pp. 904-905), which the social worker can and must uncover or master (Clark, 2000); Lum, 1999; Weaver, 1998, 1999) so as to implement "culturally appropriate interventions" (Boyle \& Springer, 2001, p. 56). Within this literature the development of "cultural competence" involves being knowledgeable about the cultural group in question, being self-reflective and sensitive to one's own biases, and integrating this knowledge and reflection with practice skills (Weaver, 1998, 1999). Miller (1988) referred to this as transactional learning where the focus is on understanding other perspectives and cultures. Lum (1999) referred to the bringing together of culturally specific knowledge, values, and skills as "bicultural integration" (p. 3; presumably those of the social worker and client from another culture). The social worker needs to use this knowledge to understand the client's worldview or "cultural frame of reference" (Clark, 2000), p. 1). The development of "practice guidelines for working with diverse populations" (p. 1) is said to aid in this process.

Although they are, for the most part, complementary, there are a number of important differences between the Indigenous and cross-cultural social work literature. First, the cross-cultural literature is aimed mainly at Western social workers in Western contexts working with people of a different culture. However, the Indigenous social work literature concerns social work practice in and for local cultures within particular local practice contexts. As such, Indigenous practice uses a grounded approach where the point of reference is the local context and Indigenous cultural practices. The main issue for Indigenous contexts is the extent to which Western social work has been imposed on local contexts by outsiders who, in the process, have overlooked local cultures (Gray, 2005). Thus authentic, culturally relevant social work practice involves applying what fits from Western social work and discarding what does not fit. It is important, when reflecting on Indigenous cultures and practices, not to romanticize the "traditional" but to question these in relation to the acceptable universals in social work, of which there are few, such as the pursuit of human rights and social justice (Gray \& Fook, 2004; Gray, 2005). As Wiredu (1980) pointed out, when writing about African culture, modernization and development bring with them a scientific and systematic approach to culture, which is not simply about the transfer of technology. In applying scientific thinking to Indigenous cultures, or any other culture for that matter, the resultant philosophy of practice must be justified on rational grounds for the continuance of particular cultural practices, both in Western and Indigenous contexts. For example, too often belief in the supernatural is attributed to prescientific traditional cultures, when, if one were to explore such practices further, one would find more witches in Europe than in Africa, though the myth is perpetuated that traditional Indigenous cultures are the main purveyors of supernatural practices.

Secondly, in both Western and Indigenous contexts, questions arise about outmoded customs or cultural practices. The difference in Western contexts is that Indigenous cultures are expected to fit in with mainstream culture, because there is an implicit belief that Western values and practices are superior to traditional ones. Crucial here is the definition of culture being used. Culture is a flexible concept, and the process of distinguishing between those aspects of culture worthy of being preserved from those that need to be abandoned is continual, in response to historical, social, economic, and political changes in the broader society (Dean, 2001). Critical evaluation of traditional philosophies is needed as much as critical evaluation of Western thinking, such as the consequences of science and progress and the devastation of the environment. In truth, there is no such thing as pure culture in Indigenous or Western contexts, and this is the main weakness of the cross-cultural literature that implies that culture is a static entity, such that one can learn about another's culture and practice in a culturally appropriate manner-the culturally appropriate manner being adopting or, at least, accepting the culture of the other uncritically. The difference in Indigenous contexts is that many of these societies are in transition from the traditional to the modern and the "process of modernisation entails changes not only in the physical environment but also in the mental outlook of ... people(s), manifested both in their explicit beliefs and in their customs and their ordinary daily habits and pursuits" (Wiredu, 1980, p.x). Such changes are slow, and people do not easily let go of their beliefs merely because they migrate to new places. Therefore, the issues raised in this article are important for social workers everywhere, whether they are working with immigrants and refugees in postindustrial societies or with Indigenous people in Oshkosh, Wisconsin, or Nome, Alaska, for example. 
Thirdly, while cultural identities might be taken for granted in Western cultures, in postcolonial situations most Indigenous people are engaged in a quest for their postcolonial identity, seeking to reclaim and preserve the best parts of their culture. Thus said Wiredu (1980): Ways need to be found to foster development and scientific progress so that the best of Indigenous culture is preserved. We contend that we can learn from the best in Indigenous culture even in Western contexts, and that, in fact, we are doing this as the literature on spirituality and ecosocial work attests. (Coates, Bray, \& Hetherington, 2006)

Fourthly, the cross-cultural literature is often silent on the question of language. Language is central to culture, as it is much more difficult, if not impossible, to preserve one's culture without retaining the language. Languages contain concepts, beliefs, and ways of understanding that convey particular Indigenous worldviews; the loss of language is the loss of a foundation for a culture. This is one of the reasons why language is highlighted in the postmodernist discourse, and why postmodernists react to the universalizing effects of globalization. For example, with the dominance of English in global cultural products, local languages - the principal tools of cultural expressionacquire the image of inferiority. More important, however, is that languages are being lost: "An indigenous language disappears every two weeks. It is estimated that by the end of the 21 st century, 5,500 of the current 6,000 languages now spoken will simply be as dead as Ancient Greek and Latin" (Sardar \& Wyn Davies, 2002, p. 126). There are words, terms, and phrases not available in English that are being lost forever, and real voices in real languages are being threatened. Thus, even when we hear Indigenous people speaking, it is almost always in a voice, in a language, that is not their own. The loss of language is one of the most pervasively damaging effects of globalization and imperialism. Those whose ancestors spoke in different and dying languages, and who had concepts and spiritual impulses not amenable to translation, feel cut off from "their own kind" when their Indigenous language is lost.

Against this backdrop, we can look critically at social work's enchantment with universal definitions and standards. We can examine the merits of universalizing trends such as these in light of social work's colonial past and criticisms of its cultural imperialism (Gray \& Fook, 2004; Midgley, 1981). We can be sensitive to Indigenous concerns with the perpetuation of colonialism through economic globalization, given the fact that in much of the less-developed Third World economic indebtedness has supplanted political subordination. In developed First World contexts, the move to global standards makes perfect sense in that it is consistent with social work's universalizing and globalizing aims to make its skills transterable across diverse countries and cultural contexts. Nevertheless, it shows lack of sensitivity to more pressing concerns in local, Indigenous contexts, such as the preservation of language and the reclamation of the best in their cultures against the onslaught of the culturally homogenizing effects of globalization. So, although the establishment of national professional standards (competencies) in many countries like Canada, South Africa, and Australia might be appropriate as social work and most other forms of knowledge become commodities, there are life-and-death issues to be dealt with as a consequence of globalization in Indigenous contexts. A profession so avowedly committed to human rights and social justice cannot overlook these issues.

The indigenization literature also cnables us to take a more critical look at notions of cultural competence and the idea that one can become competent in the culture of another. Cultural competence is a modernist idea that is "consistent with the belief that knowledge brings control and effectiveness, and that this is an ideal to be achieved above all else" (Dean, 2001, p. 624). Thus it treats "cultural categories or groups as ... static and monolithic with defining characteristics that endure over time and in different contexts" and "involves learning about the history and shared characteristics of different groups ... using this knowledge to create bridges and increase understanding with individual clients and families" (Dean, 2001, p. 625). More contemporary postmodern views see understanding of culture as individually and socially constructed, as "always contextual, emergent, improvisational, transformational, and political" (Laird, in Dean 2001, p. 625; see also Dean, 2001; Fook, 2002); as a dynamic, living thing, constantly being molded and shaped by diverse influences at play at any one time, which molds and shapes us as we attempt to understand it (Gray \& Allegritti, 2003). Ience, postmodernists question the notion that we can become competent at something as complex as another's culture. The indigenization literature shows how much people's identity is linked to their culture and how difficult it is to understand culture from the outside in. Culture is not something we can put on and take off like a cloak. We are cmbedded in our culture and its rituals, practices, and ways of doing things-hence Laird's (1998) observation that we ought to shift the focus of our discussions on cultural differences to ourselves and find ways to better understand our own culture so as to make us more sensitive to other's cultures. The best we can do is to accept our lack of competence in crosscultural matters and realize that working across cultures is not so much about "knowledge" as about "understanding" (Dean, 2001, p. 624).

With "lack of competence" as the focus, a different view of practicing across cultures emerges. The client is the "expert," and the clinician is in a position of seeking knowledge and trying to understand what life is like for the client. There is no thought of competence-instead, one thinks of gaining understanding (always partial) of a phenomenon that is evolving and changing (Dean, 2001, p. 624). 
Thus, the indigenization literature teaches us that it is wise to maintain a healthy skepticism to modernist ideas like cultural competence, because it is questionable to assume that "one can become competent at the culture of another" (Dean, 2001, p. 623) and it is not easy to "comprehend the perspective of ... others differently located" (Young, 1999, p. 127). The focus on the lack of competence rather than the possibility of cultural competence is a sociologically realistic and fruitful position because it shows that one way of gaining an understanding of the other's culture comes about through the process of communication, because "understanding comes, if it comes at all, only by engaging in a volley of practical dialogue" (Tully, 1995, p. 133). The process of cultural understanding is ongoing and is never complete. It proceeds in stages. As we gain an understanding of the other's culture, it changes our previous ideas and interpretation, and we redefine our knowledge accordingly. As our understanding changes through cross-cultural or intercultural interaction, communication or dialogue, we then strive to gain further knowledge about the other's culture. It is this emphasis on dialogue, discussion, and communication that directs our attention to the fact that our interactions are intercultural, transcultural, or cross-cultural, whichever term one prefers. There is an ongoing international debate about intercultural or cross-cultural communication that examines what happens in the process of talking to the cultural other (Benhabib, 2002; Habermas, 1994; Taylor, 1994; Tully, 1995; Young, 1999).

Another lesson from the Indigenous literature is that while culture is not homogeneous, neither is it internally consistent. In fact, a culture is always made up of several cultures-historically, cultures have never existed alone or in isolation. In Indigenous communities, culture has been historically imposed, through colonization and imperialism. Since the beginning of history, people from different cultures have interacted in a voluntary capacity. They have inter alia exchanged goods, intermarried, fled from religious or political persecution or poverty, and emigrated. In the process, there has been a greater blending of cultures than national histories have made out. This is the strength of the postmodernist position. It has discredited the Enlightenment notion of culture and the view that individuals are located "in independent, closed and homogeneous" (Tully, 1995, p. 14) cultures and societies. It has introduced the idea that individuals are members of cultures that are "densely interdependent" and overlap, interact, and are negotiated (Tully, 1995, p. 10-11).

The cross-cultural literature tends to look for congruencies, commonalities and similarities rather than to recognize that intercultural interaction, even in professional settings, requires that we leave behind our cultural comfort zones; listen to the different ways, philosophies, and practices of the cultural other; change and expand our established views on their cultures; and, most importantly, keep an open mind. One of the starting points in discussing culture from a contemporary, postmodernist position is to recognize that culture is a contested concept, or, as Benhabib (2002) pointed out, "cultures are constituted through contested practices" ( $p$. viii). To learn from the indigenization literature, openness to such understanding is essential.

\section{Indigenization, Ecology and Spirituality: Hearing Indigenous Voices}

The growing acceptance of Indigenous social work has arisen, in part at least, as a consequence of providing services to increasing numbers of immigrants from nonWestern countries, the recognition of the value of alternative worldviews, the resurgence of interest in spirituality, and growing awareness about environmental degradation. This has been a complex, rather than a linear, process. Recent decades have witnessed the systemic challenge to the social order that may best be described by the term industrial modernism. This period has seen the intensification of globalization, the end of the Cold War, liberation struggles in many countries, the threat to human well-being resulting from human-initiated environmental problems, a quest for economic domination of the Third World by the First World, terrorism, and the search for security that accompanies such massive changes. In this period of rapid change, which seems to some like chaos, old paradigms - most notably modernism-have been challenged as the guidelines they provide are no longer effective (see Berry, 1999). As a consequence, large numbers of people, in all parts of the planet, are facing great uncertainty and returning to reactionary beliefs (e.g., fundamentalist Islam in the Middle East and evangelical Christianity in the West). This divide is appearing within professions and academic disciplines, as well as in faith traditions.

However, we have also been witness to the groundswell of social movements that, taken together, argue for significant changes to the current structure of society, for example, movements such as holistic medicine; antinuclear, peace, and disarmament; sustainability; process theology; voluntary simplicity; ecofeminism; and goddess worship (Capra, 1982; Elgin, 1993; Sahtouris, 1989; Swimme, 1998; Swimme \& Berry, 1992). These alternative perspectives have been reinforced by scientific discoveries, such as quantum mechanics and evolution, which have shifted understanding of nature and of humanity's relation to it. For example, the concept of nature is shifting from an unchanging mechanistic (dead) universe, to an unfolding, organismic, creative cosmos in which humans can play a significant role. Although postmodernism helps us to understand this surge to a multiverse of perspectives in which alternative points of view are debated, it will not solve the problems of fragmentation and domination inherent in modernism 
(see Coates, 2003). Postmodernism served to expose the "soft underbelly" of modernism by challenging universalisms, focusing on the social construction of knowledge and drawing attention to the inherent allocation of power that flows from privilege. The challenge to universalism made it possible for the voices of the marginalized to be heard.

The discomfort that the postmodern deconstruction created has contributed to the questioning of foundational assumptions and the renewal of interest in the search for meaning. The resurgence of interest in spirituality and ecology over the past two decades has arisen, at least in part, to meet this need. It is a consequence of the breakdown of security that has resulted from postmodernism and other global challenges (such as postmodernism's critique of metanarratives, the recognition of marginalized voices, the critique of colonialism, the ascent of anti-oppressive practice,

Indigenous movements usually involve

people collectively asserting their rights for

self-determination since Indigenous people

recognize that political, economic,

educational, and health benefits and

privileges cannot occur as long as the

entire population is disenfranchised. of thought have come to similar conclusions from different paths (e.g., ecofeminism and deep ecology), some writers have argued that Indigenous beliefs can guide humanity (Berry, 1997). As a result, Indigenous beliefs and values have gained recognition and credibility among the worldviews that provide a reconceptualization of the universe and humanity's relationship to it. In social work this has opened avenues of acceptance toward Indigenous approiches to helping.

The growing acceptance of the indigenization of social work has occurred along with increasing recognition of the need for alternatives to economic and cultural globalization, such as local currencies, community-supported agriculture, right-sized organizations, and ecoregionalism. This is consistent with the centrality of diversity inherent in alternative cosmologies. For social work, this has led to the valuing of diversity and the need to ensure that services are culturally relevant. Such changes have pushed social work beyond technology transfer and cultural sensitivity, toward the integration of social work principles with Indigenous beliefs, values, and rituals, and the corresponding adaptation of its technologies. In Canada, for example, this is reflected in the development of social work programs that are not only dedicated to First Nations students and services but are also focused on the delivery of services within First Nations communities. This type of social work education no longer attempts only to present dominant social work theories and interventions and discuss later how these may be relevant. The focus has shifted to an identification of needs and the application of traditional methods of healing. Greater attention is being given to such traditional practices as healing circles, smudging, sweats, and spirit quests, to name a few. Provincial laws must still be adhered to, and interventions that are more traditional to social work are adapted when appropriate, but the focus of education for Indigenous social work has shifted. Themes of harmony, balance, connectedness, and sufficiency in Indigenous social work literature, as well as the literature on spirituality and ecosocial work, have come to replace exploitation and progress, economism, individualism, and consumerism. The case studies that follow show how these Indigenous themes are entering mainstream social work discourse. 


\section{Making Social Work Practice Authentic to Local Culture: Some Indigenous Case Examples}

There is widespread acknowledgment in the social work literature for both the Western and non-Western world that social work as a profession is a product of culture, and that culture plays a critical part in its construction. The discovery (or rediscovery) of the diversity and uniqueness of local culture has led some academics and practitioners to question the relevance of applying Western models of social work practice to non-Western contexts. This emerged, in part from the recognition of the lack of goodness of fit in directly transplanting Western social work knowledge and practice to nonWestern communities (Haug, 2001, 2005; Nagpaul, 1993; Nimmagadda \& Cowger, 1999). Hence, various authors have called for the indigenization of social work practice. According to Shawky's (1972) early definition, indigenization is essentially about "adapting imported ideas to fit local needs" (p. 2). However, as Ling (2004) noted, "the quest for appropriate social work practice for nonWestern countries and for non-Anglo-Saxon communities in Western countries has in more recent years moved from an indigenization ... approach to that of an authentization or [a] culturally appropriate approach" (p. 336). The term authentization, which also means "to become genuine" or "to go back to one's roots to seek direction," was first coined by several Egyptian writers, (Ragab 1982, 1990; Walton \& Abo El Nasr, 1988). The philosophical approach of authentization urges social workers in nonWestern contexts to move away from simply adapting and modifying Western social work theory and practice to that of generating knowledge and practice models drawing on the values, beliefs, customs, and cultural norms of Indigenous helping practices and local Indigenous cultures. It is argued that through this process of "indigenization from within," whereby local culture is used as a primary source for knowledge and practice development, social work practice can become culturally appropriate and relevant.

In the past decade, there has been increasing investigation using qualitative and ethnographic research methods, in exploring the lived phenomena of Indigenous social work practice in non-Western countries and contexts. There are a number of Indigenous case studies both nationally and internationally that examine the everyday interactions and interpretations of what Indigenous social workers on the ground are doing in practice. Fei (1998) described this as "seeking to know from the actual context by knowing one's own culture in its actual context" (p. 3). This social constructionist approach recognizes that there are "many ways of knowing" as people are constantly making meanings and defining their own situations. The following case studies highlight the importance of local culture and knowledge in the development of genuine and authentic, culturally relevant social work practice.

\section{Case Example 1: India}

Nimmagadda and Cowger (1999) conducted qualitative research with Indian social work practitioners in an alcohol treatment center. They concluded that Indigenous social workers self-consciously used cultural beliefs, such as dharma (duty) and karma (fate), as a directive for practice in developing their own innovative methods appropriate to local contexts. These Indian social workers had "distinctive ideas about advice giving, family intervention, confrontation and reassurance that were at variance with Western models of practice and practice behaviours" (Nimmagadda \& Cowger, 1999, p. 274).

Advice giving. Giving advice was found to be prevalent and was often cited as an important intervention for the social workers in this study. Social workers in India are perceived to be gurus or teachers whose dharma as part of their role is to impart knowledge and wisdom. In accordance with this view, clients in India regard social workers as authority figures and expect to be given guidance and instruction on the best ways to address their problems. Social workers are also perceived by clients to be "doing good karma" by the nature of their role and involvement in the helping process. The social workers in this study considered giving advice as an important aspect of fulfilling duty or tharma. As one Indian social worker explained, "I feel it is my duty to see to it that the patient is on the right path" (p. 268). Nimmagadda and Cowger (1999) found that giving advice was an effective social work strategy used in this context because first and foremost clients expected it. In addition, being more directive also worked in practice because of its alignment with local cultural norms that emphasized self-control and maintaining harmony.

Giving advice has also been shown to be part of culturally appropriate social work practice in other cultural contexts. For example, Ling (2003), drawing on research in Sarawak, Malaysia, found that giving advice was a common strategy used in local helping practices. Participants in this study gave advice to clients to minimize problems, avoid conflicts, and emphasize local cultural values of harmony and stability. Similarly, Cheung and Liu (2004) found that a more directive approach was used by Chinese social workers, as clients saw them as having both authority and knowledge and came to them for advice and direction with their problems (p. 121). This approach was applicable given the cultural norms regarding the way in which Chinese people were taught to respect authority and the fact that individuals were not encouraged to make decisions by themselves. It should be noted that in these three contexts authority is not associated with the Western concept of powerlessness, but rather authority is enacted through status, rights, and responsibilities as deemed by dharma or the social order. 
Reassurance. The technique of making reassuring blanket statements such as "do not worry" was often used by social workers in this setting. Not unlike the rationale behind advice giving, Nimmagadda and Cowger (1999) linked this strategy to the perception of social workers as authority figures and the associated client expectations. Indian social workers identified reassurance as an important tool to increase client motivation. They also believed that by giving reassurance they were promoting hope for the client and family

Family intervention. Direct and indirect involvement of family and community support was considered to be an essential aspect of intervention in the helping process. The family or kin network still remains the most central social institution in Indian society. Nimmagadda and Cowger (1999) noted that when the alcohol treatment center was initially established just over two decades ago, social workers did not involve the family in their work with clients. However, family members would always accompany clients, and other friends and relatives would always visit. Consequently, social workers began to turn their focus toward family intervention. As part of fulfilling dharma, family members have a duty to help the client toward recovery. It is also the duty of clients to be responsible in the process of rehabilitation. In this context, the locus of helping activity is not the isolated on the individual, as the individual is defined by and operates through a collective unit. Maintenance of collective harmony then becomes a key factor in understanding social work practice intervention in India. Including family in all aspects of social work intervention was found to be an effective strategy for participants in this study because it emphasized cultural values in relation to communal responsibilities and the interconnectedness of people. In fact, Indian social workers in this study referred to family members as "pscudo-counsellors" (Nimmagadda \& Balgopal, 2000, p. 270).

In this example from India, reinforced by examples from Malaysia and China, social work practice can be viewed as part of dharma, by working with and through the sense of social norms, cultural stability, and harmony. Involvement of family and community members uses naturally occurring support networks and this is also related to cultural themes of interdependency and harmony. Thus even though the individual may be the focus of help, the family or community are seen to be intrinsically connected to clients and involved in the helping process either directly or indirectly. This is in line with a culturally relevant Indian worldview that emphasizes communal responsibilities and the interconnectedness of people. A similar worldview exists among Indigenous Australians (Bennett \& Zubrzycki, 2003; Collard, Crowe, Harries, \& Taylor, 1994; Thorpe, 1997).

\section{Case Example 2: Canada}

Among First Nations groups in Canada, Hart (2002) has articulated an Aboriginal approach to helping that incorporates many elements of an Aboriginal worldview and its assumptions about the nature of helping. Central to Hart's approach is mino-pimatisiwin, a Cree word for the good life in which people and communities take responsibility for healing and growth. The good life includes "holistic wellness" or wellness in all aspects of life - physical, spiritual, emotional, and cognitive-based on connection, relationship, balance, and harmony. These values are seen to support a person's or community's search for mino-pimatisiwin. "Native cultures emphasize cooperation, harmony and collective responsibility. Thus the goal (of self-actualization) is more akin to family and tribal self-actualization" (Herring, as quoted in Hart, 2002, p. 44). Elders play an important role within the family and community and are able to enrich connections to history, rituals, strengths, and challenges. They are "seen as individuals who understand themselves in relation to the universe around them.... These well respected people have the ability to transmit the culture" (Hart, 2002, p. 58). Thus, a core element to this Aboriginal approach is the importance that historical factors (personal, family, community, and nation) have on the current situation. Attention to history recognizes the impact of "colonization, oppression, and social work's role in these destructive processes" (Hart, 2002, p. 23) on individuals (e.g., internalized oppression) and on communities (e.g., the loss of traditional ways of life). Foundational concepts include the following sections.

Wholeness. This is described as "the incorporation of all aspects of life and the giving of attention and energy to each aspect within ourselves and the universe around us" (Hart, 2002, p. 41). Spirituality and connection to the land are innate elements of wholeness. Attention is given to both the conscious and unconscious (visions, dreams), and self-reflection is important for both individuals and communities.

Balance. Attention is given equally to all parts so that one part of a person is not focused on to the detriment of other parts. This includes consideration of the "wellness of all beings" (Hart, 2002, p. 41), such that personal wellness does not harm others.

Connection. A person's or community's well-being includes consideration of relationships. Disconnection, both disconnection within oneself or with family, community, or nation is perceived as a cause of problems.

Harmony. Wellness involves being at peace with oneself and life around you, which involves being in harmony with yourself, family, community, nation, and all living things.

Within this approach, healing and helping involves restoring relationships that are out of balance and harmony, or are disconnected. An important consideration is respect for each individual's and community's right to self-determination. Humility, listening, patience, sharing, 
and storytelling are essential practices in helping people and communities to find their own path. Healers must also be on a path toward mino-pimatisiwin and must live the life they wish for others. As a result, the responsibilities expected of people seeking help are also expected of the healer/helper. They are seen as role models, and there is considerable mutuality as helpers can be expected to share learning from their own experiences.

\section{Case Example 3: Tonga}

Mafile'o (2004) discussed two Tongan social work concepts: fakafokau'aki (connecting) and fakatokilalo (humility), drawing on qualitative research exp-

loring the practice of Tongan social workers in New Zealand.

Fakafekau'aki (connecting). In this particular study, this term was consistently described by Tongan social workers as a key dimension of practice. Fakafekan'aki is a verb that means to bring into relationship with each other and also refers to something being reciprocated between two or more people. This process of connecting occurs between a social worker and client when they establish an association of belonging to each other. As one Tongan social worker stated, "so, first and foremost, relationship and connections are important. So if you wanted a strategy for helping ... it is about alliances, it's about friendships.... Step one: build some rapport, build some friendship, build some alliance" (Mafile'o, 2004, p. 240). Mafile'o (2004) explained that this connecting may be based on genealogy, church affiliation, or shared knowledge of people or places. Fakafekau'aki involves a significant degree of self-disclosure on the part of a social worker in sharing personal information with the client as to religion, family genealogy, and whether the social worker is New Zealand or Tongan born. This is in contrast to mainstream Western social work practice regarding the maintenance of professional boundaries. However, it provides an effective base for a helping relationship to proceed. One participant described how she was having dificulty in obtaining cooperation from a family to locate a young person who had run away from home. When the family learned the social worker's surname and was able to make a connection, this opened the door for information sharing, and the young person was successfully located.

Fakatokilalo (humility). This term is a verb that essentially means to be humble and was also described in Mafile'o's (2004) study of Tongan social workers as an important aspect of social work practice. Fakatokilalo requires social workers to step down from their position of status or authority, in order to be lifted up by those with whom they work so they can develop engaging and sustaining relationship with their clients. In this context humility is both a value and practice that enhances effectiveness of the helping relationship and bring about a reciprocal response. Fakatokilalo may be demonstrated by taking one's shoes off at the door; making understatements about what one has to offer others; allowing others to speak; and doing service roles, such as washing dishes or preparing food.

In Tongan culture relationships are often not individualized but are governed by one's social position and roles in a network of connections. Mafile'o (2004) described Tongan culture as hierarchical, whereby social status is typically based on factors such as rank, age, and family background (showing similarities to the Malaysian and Chinese examples). One young female participant working in a school social work setting stated that she took a backseat with parents and introduced herself as her parents' child. This allowed her to effectively connect as well as portray her humility in not asserting her professional status as a social worker. This was particularly important because of her young age. Similarly, the emphasis on respect through the avoidance of being assertive demonstrates compliance with social norms where the self is part of the community. The process of practicing these two concepts does not align well with Western notions of professionalism. However, by not asserting professional identity, Tongan practitioners are constructing social work practice so they can practice effectively within Tongan culture. Moreover, Western social work's emphasis on relationships based on maintaining professional detachment may be perplexing to clients in a culture that values mutuality and reciprocity.

Similarities to the use of comnecting and humility can be found in social work practices in Indigenous Australia, India, Maori/New Lealand, Hawaii, Malaysia, and Samoa. Bennett and Zubrycki (2003) conducted qualitative research with Aboriginal and Torres Strait Islander social workers in Australia. They found that during the introduction process these social workers used self-disclosure to enhance the helping relationship and establish credibility. This use of self involved identifying birthplace and kinship ties, and it could also involve sharing personal stories and life experiences. Similarly, Nimmagadda and Cowger (1999) found that as a related consequence of the focus on 
family intervention in India, there was less emphasis on keeping the personal and professional apart, and more personal relationships were formed and maintained with the whole family. Maoris talk about "group rhythm" and the importance of gathering and uniting together. This sense of belonging also can involve sharing biographies, personal histories of people, and relationships to each other.

In Hawaiian culture an individual is also defined in the context of relationships with family, community, the land, and the spiritual realm. Three integral values that reflect their culture are ialima (cooperation), kokua (helpfulness) and lokahi (unity). Each individual family member or group has defined roles and goals. Contributions to unity and harmony are considered to be far more important than self-satisfaction or meeting one's own needs (Ewalt \& Makuau, 1995). Hawa Ali (1991), writing about earlier research conducted in Malaysia, described the family unit as the foundational social caring system. Similarly, at the community level, mutual help (gotong-royong) and cooperation (keriasama) have always been cited as the attributes that keep the community together. In Samoan culture sharing is also an integral part of life, and attached to this notion is the cultural expectation of reciprocity. This process may involve sharing food or household items or attendance at cultural events or ceremonies. Many cultures emphasize the value of the collective over the individual, and strengthening group cohesiveness and stability is an integral part of life. Individuals are characterized by social relationships and a shared identity that comes from "sharing food, water, land, spirits, knowledge, work and social activities" (Linnekin \& Poyer, 1990, p. 8).

\section{So What Might Mainstream Social Work Learn From Indigenous Cultures?}

As shown in the case examples, interventions based on concepts like individualism, objectivity, and professional distance inherent in Western conceptualizations of social work practice would not be as effective and, in fact, may be alienating for some cultures. Although these case examples provide us with demonstrations of genuine, authentic social work practice-in that the cultural themes underlying these approaches are compatible with the profession's core values of respect and social justice-they are, at the same time, grounded in the beliefs of local people. 'There is thus a mutuality of worldviews and the possibility of some aspects of a universil social work emerging. However, to address the question we posed at the outset of this article, we will end with an enunciation of some important aspects of these local cultures that can enrich mainstream, culturally relevant social work practice and thus contribute to its universality:

Indigenous approaches remind us of our humanistic goals and the importance, first and foremost, of connecting with the dient. While mainstream social work is replete with models for engaging with clients, enhancing communication processes, and developing a healthy helping relationship, the most important aspects of connecting with others is grounded in the everyday lives of our clients. If we can reach clients where they eat, live, and play, and if we can encounter them in the systems that are meaningful to them and understand the relevance of their cultural beliefs and practices, then will our practice be relevant to their needs.

Indigenous worldviews strengthen and enrich social work knowledge and practice. They remind us that there are many ways of knowing, that science has limitations, and that culture need not be accepted uncritically. These alternative voices draw our attention to our common humanity, to the importance of family and community, to the importance of celebration and ritual, and to the values of humility and compassion. These cultural practices provide some measure of certainty in an otherwise uncertain world.

Indigenous thinkers question the universality of social work knowledge, but leave open the possibility for shared values and discourses provided that mainstream social work can open itself up to the lessons Indigenous cultures have to offer. They remind us not to accept uncritically the idea that Western social work has universally relevant methodologies, that universal standards are desirable, and that an international professional identity for social work will necessarily be valued in non-Western countries and contexts. When people think that ideas are being imposed on them without regard for their culture, they will resist and challenge such cultural imperialism. Wo learn, too, that in postcolonial situations, there is a need to break free of Western conceptions so that people can recover their own cultural identity (Wiredu, 1980). Where else can they find it than in the rediscovery of the old, Indigenous ways of knowing and helping, grounded in the worldviews and cultures of local contexts? Sifting through this and working out what fits the transition from traditional to modern is a process, and a new culture will emerge, one that is distinctly African or Chinese or Indian or Hawaiian or Malaysian or whatever the native culture may be.

Indigenous cultures challenge the dualistic notions of Western thinking. Kissman and Maurer (2002) reminded us that "Eastern and Western healing practices are not opposites but share common attributes... Wellness is enhanced by the emphasis on humility, gratitude, connectedness with self and others, present-moment awareness, sharing and listening to stories ... the quieting of the mind to cope with stress and worries, speaking to and listening to a higher power and bridging the gap between mind and body" (pp. 35-36). Much of this thinking is holistic, rooted in place, in harmony with nature, and preserving the wellbeing of all life-forms. Indigenous approaches remind us of the importance of context. 
Indigenous approaches demonstrate the importance of valuing both Western and non-Western knowledge, yet of accepting neither uncritically. Concrete practice examples, such as those presented here, release Indigenous ways of knowing from preconceptions that they are exotic or romantic. They remind us that we are all grappling with the same questions about the meaning of suffering and hardship. Generally, non-Western peoples (particularly from India and certain parts of Asia) may be more accepting of hardship because they take the view that many life events are subject to external control of a transcenctental nature. For example, although clients in India may complain about fate (korma), they can also ascribe their problems to it, and this also externalizes the causes of their problems (as we do in narrative therapy in Western social work). Similarly, the belief in fate also has positive outcomes when it helps clients to accept their problems with equanimity.

Indigenous cultures remind us that self-fulfillment can only be realized in group fulfillment. They help us counter the worst consequences of individualism and draw attention back to the importance of family, kin and social networks, and community.

Through these examples, social work practice can understood as taking on a distinctive character wherein Indigenous ways are providing mainstream Western social work with new and innovative approaches. In short, there is much for Western social work to learn from Indigenous helping principles and methods.

\section{Conclusion}

The bulk of the literature on cross-cultural social work is geared toward Western social work's embrace of culturally sensitive practice through use of antioppressive and cultural competence practice models. We highlight differences and similarities in the way in which notions of culture are used in the cross-cultural and Indigenous literature, pointing to the main issues each seeks to address. These include, for example, sensitivities in the Indigenous social work literature toward universalizing and globalizing forces that continue the colonization process, and claims in the cross-cultural anti-oppressive practice literature that mainstream social work silences other voices. We contend that alternate voices are finding expression through the literature on spirituality and environmental or coosecial work, noting that, in fact, in some contexts where social workers and Indigenous communities have been interacting, their discourse has progressed beyond multiculturalism and cultural sensitivity to embrace Indigenous thinking in mainstream practice. In other words, they have proceeded beyond awareness of culture to making culture explicit in their education and practice. By presenting several case examples, we draw attention to ways in which Indigenous social work enriches mainstream understanding of culture. Further, we attempt to develop the theoret- ical dimensions of cross-cultural social work by showing how Indigenous social work relates to cultural competence and how lessons from Indigenous contexts can inform culturally relevant practice. (Our article aims to open up these issues-not to prescribe practice or develop models. These are insights that can shift our thinking on some very important issues in social work about which all social workers should be aware.

\section{References}

Adams, (. ( Ed.). (1993). Foofimmsm and the sacrol. Now lork: (ontinumm.

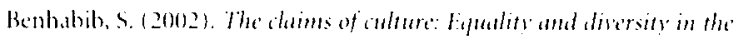
global era. Princetom, NJ: Princetum L'niversity Press.

Bennett, B., \& Zubroki, I. (2003). Hearing the storien of Aboriginal and Torres strait Jslander social workers: (hallenging and changing the system. Alustralian Social Woth, $56(1), 61-70$.

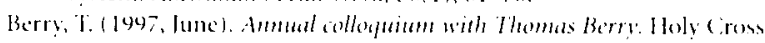
Centre for foology and Spirituality. Port Burwell: ()ntario, Candat

Berry, l. (1999). The great woth: (Her wat into the future. New lork: Bell lower.

Besthorn, 1: (1997). Reomieptualizing social works person-in-entromment perspective texplonations in radical emirommental thowsht. Enpublished Inoctoral dissertation, Lniversity of Kansals.

Buyle, D. I., \& springer, A. 120011 . 'Jowards a cultural competence measure for social work with specilic population. Jourmal of Ethme

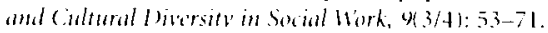

(apra, f (1982). The turning pomb. New York: Simon \& Sihuster.

(heung, M.. \& liu, M. (20M4). The self-comeept of (hinese women and the indigenization of soial work in China. International Soctal liork, $4711,109-127$

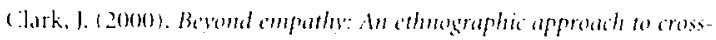
culnaral social work pratice. Toronto, Canada: Lniversity of lioronten liculty of Social Work.

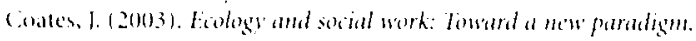
Halifax: Fermwood leress.

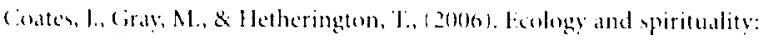
Iinally a place for Indigenous social work. British fourmal of Social Wirk. 30, 381-399

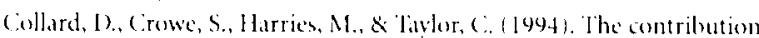
of Aboriginal families values to Australian family life. In I. Inglis 8 1. Rogan (Eds.), Hexible families: New dircthons for Alustalion commanities (pp. 113-120). Sydney: Pluto Press.

1)ean, R. (2001). The myth of cross cultural competence. Fomilhes in Soriets: $82(6), 623-630$

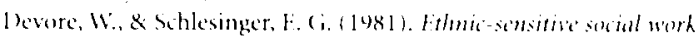
practiac: New Gork: Macmillan.

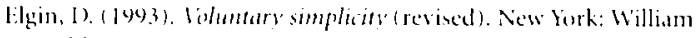
Norrow:

Iwalt, P.. \& Makuau, N. (1995). Sell-determination from a Pacifie perspective social Hork, $4(x 2), 108$.

Fei, X. (1998). Con fansidas wenhua gijuche iiasliu | From reflection to cultural self-consciousness and communication|. Mushu, 2.36, 3-8.

Fook, I. 2002 1. Social work: Critical theory and practice london: Sage.

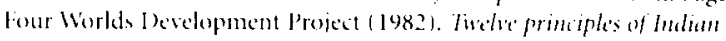

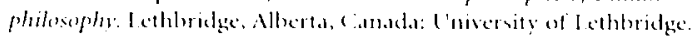

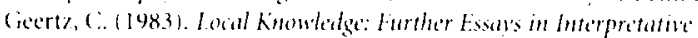
Anthropologes: New lork: BasicBooks.

Ciraty, M. (20051. I )ilemmas of international social work: Paradoxical processes in indigenisation, imperialism and universalism.

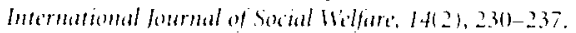

(iray, M., \& Allegritti, l. (2002). Cross-cultural pratice and the indigenisation of African social work. Social Hork/Natuskaplike lierk, $38(4), 324-336$

(irav, M., \& Alegritti, [. 12003). Lowards culturally sensitive social work pratice: Re-examining soss-sultural social work. Sortal

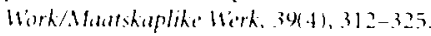


(iray, M., \& Fook, J. (2004). The quest for a universal social work: Some issues and implications. Social Work Eilucation, 23(5), 625-644.

Habermas, J. (1994). Struggles for recognition in the democratic Constitutional State. In A. (iutman (Ed.), Multiculturalism: Examining the politics of recognition. Princeton, NI: Princeton University Press.

Hart, M. (2002). Secking mino-pimatiswin: An aboriginal approach to helping. Halifax, Canada: Fernwood Press.

Haug, E. (2001). Writing in the margins: Critical reflection on the c'merging discours' of international socul work. Unpublished Master's thesis, University of Calgarv, Calgary, Canada.

Haug, E. (2005). Critical reflections on the emerging discourse of international social work. International social Work, $48(2)$, $129-135$.

Hawa Ali, s. (1991). Western theory and local practice: Implications for social work practice in Malaysia. Asia Pacific Journal of Social Work, (1), 26-47.

Kissman, K., \& Maurer, I. (2002). East meets west: Therapeutic aspects of spirituality in health, mental health and addiction recovery. International Social Work, 45(1), 37-4.3.

Laird, J. (1998). Theorizing culture: Narrative ideas and practice principles. In M. Mc(ioldrick (Fd.), Re-visioning family therapy. New York: Giuilford Press.

ling, H.K. (2003). Drawing lessons from locally designated helpers to develop culturally appropriate social work practice. Asia Paifici Journal of Social Work, 1,312), 26-44

ling, H.K. (2004). "The search from within: Research issues in developing culturally appropriate social work practice. Imermational Social Work, $47(3), 336-345$.

L.innekin, I., \& Poyer, L. (1990)). Introduction. In I. Linnekin \& Poyer, L. (Eds.), Cullural identity ami cthnicity in the Paifi: Honolulu: University of Hawaii Press.

L.um, D. (1999). Culturally competent practice: A framework for growth and action. Belmont, CA: Brooks/( cole

Mafile'o, T. (2004) Exploring Tongan social work: Fakafekau'aki (connecting) and fakatokilalo (humility). Qualitative Social Work. 3(3), 239-257.

Midgley, I. (1981). Professional imperialism: Social work in the Third World. London: Ileinemann Educational Books.

Miller, J. (1998). The holistic curriculum. Toronto, Canada: Ontario Institute for Studies in Fducation.

Natss, A. (1989). Ecology, community and lifestle (1). Rothenberg, Trans. \& Ed). Cambridge, UK: Cambridge University Press.

Nagpaul, H. (199.3). Analysis of social work teaching material in India: The need for indigenous foundations. Int'rnational Social Work, 36, 207-220.

Nimmagadda, J., \& Balgopal, P. R. (2000). Indigenization of social work knowledge: An explorition of the process, Asia Pacific fournal of Social Work, $10221,4-18$.

Nimmagadda, I., \& Cowger, C. (1999), Cross-cultural practice: Social worker ingenuity in the indigenization of practice knowledge. Intermational social Work, 22(3), 261-276.

Ragab, I. (1982). Aluthentization of soctal work in seveloping contrie's. Egypt: Integrated Social Services Project.

Ragab, I. (1990). How social work can take root in developing countries. Social Development Isste's, 12(3), 38-51.

Sahtouris, E. 1 1989). (iana: The human journey from chaos to cosmos Toronto, Canada: Simon \& Schuster.
Sardar, 7. \& Wyn Davies, M. (2002). Why do people hate America? Cambridge, UK: Icon Books.

Shawky, A. (1972). Social work education in Africa. International Social Work, 15(1), 3-16.

Spretnak, C. (1997). The resurgence of the real. (Ontario, Canada: AddisonWesley.

Swimme, B. (Producer) (1998). The Rarth's imagimation (Motion picture). (Available from (enter for the Story of the Universe, 311 Rydal Avenue, Mill Vallev, (A).

Swimme, B., \& Berry, T. (1992). The universe story. San Francisco: Harper.

Taylor, C. (1994). The politics of recognition. In A. Ciutman (Ed.). Multiculturalism: Examining the politics of recognition. Princeton, NJ: Princeton University Press.

Thorpe, R. (1997). Indigenous challenges to the social work and social welfare codes of ethics in Australia: A critical issue for social welfare education. Northern Radius, 4(2), 9-10.

Isang, A. K.T., \& Yan, M-C. (2001). Chinese corpus, western application: The (hinese strategy of engagement with western social work discourse. International Social Work, 44(4), 43.3-454.

Tsang, T., Yan, C.., \& Shera, W. (2000). Negotiating multiple agendas in international social work: 'The case of (hini-Canada collaborative project. Canatian Social Work Review. 2(1), 147-161.

Tully, J. (1995). Strange multiplicity. Cambridge, UK: Cambridge University Press.

Walton, R., \& Abo Fl Nasr, M. (1988). Indigenization and authentization in terms of social work in Fgypt. International Social Work, 31. $135-144$.

Weaver, $\mathrm{H}$ (1998). Indigenous people in a multicultural society: Unique issues for human services. Social Work, 43(3), 203-212.

Weaver, H. (1999). Indigenous people and the social work profession: Defining culturally competent services. Social Work, $44(3)$. $217-227$.

Wiredu, K. (1980). Philosophy and an Airican culure. Cambridge, UK: Cambridge University Press.

Yip, K. (2004). A (hinese cultural critique of the global qualifying standards for social work education. Social Work Education, 2.3(5), $597-612$.

Young, M. (1999). Residential segregation and differential citizenship. Citizenship Studies, 3(2), 237-252.

Mel Gray, PhD, is professor of social work, University of Newcastle. John Coates, PhD, is professor, I epartment of Social Work, St. Thomas University, Canada. Tiani Hetherington, is Phl) student, University of Newcastle. Correspondence regarding this article may be sent the first author at Mel.Cray@newcastle.eduau or University of Newcastle, University Dr., Callaghan, 2308 NSW, Australia.

Authors' Note. An adapted version of this article will appear in (;ray, $M$. Coates, J., \& Yellow Bird, M. (Eds). Indigenous social work around the world. Hants, England: Ashgate.

Manuscript received: February 24, 2005

Revised: April 25, 2005

Accepted: April 27, 2005 